\title{
The role of inflammation in schizophrenia: an overview
}

\author{
O papel da inflamação na esquizofrenia: visão geral
}

Over the recent years, there has been a return to the hypothesis that immune factors are associated with schizophrenia. At the same time, neuroscience studies have indicated an important role of the immune system in neurodevelopment through the modulation of different neural processes, including brain plasticity and regulation of neurotransmitters. ${ }^{1}$

Early observations of the involvement of the immune system in schizophrenia suggested an association between infection and psychotic symptoms and indicated an increased risk of psychosis after hospitalization for the treatment of infectious conditions. ${ }^{1}$ Those findings could be explained by the action of infectious agents (e.g., human immunodeficiency virus [HIV]) and neurotoxic factors associated with proinflammatory cytokines. Several autoimmune diseases have been associated with a higher incidence of psychotic disorders, including systemic lupus erythematosus, multiple sclerosis, and Guillain-Barré syndrome. An interesting nationwide cohort study conducted in Denmark ${ }^{1}$ showed that previous history of autoimmune disease and previous hospitalization due to infection increased the incidence of schizophrenia by 36 and $60 \%$, respectively. The combination of both factors had a synergistic effect, increasing the incidence rate by $125 \%$. Moreover, the incidence of schizophrenia was directly proportional to the number of severe infections and inversely proportional to the time elapsed since the last severe infection. Other epidemiological studies, including prospective cohort studies from birth, have indicated that infections in the prenatal period are associated with a higher relative risk of schizophrenia. ${ }^{2}$

The most parsimonious model proposed to explain the findings above suggests that the process is mediated by the activation of microglia and the release of proinflammatory cytokines. During neurodevelopment, microglial cells produce neurotrophic factors that regulate synapse formation and the neuronal pruning process.
Moreover, cytokines produced by the mother can cross the placenta and the blood-brain barrier. Proinflammatory cytokines such as interleukin-6 (IL-6) and tumor necrosis factor-alpha (TNF-a) play central roles in the cytotoxicity process and are associated with oxidative stress and activation of the hypothalamic-pituitary-adrenal axis. ${ }^{3}$

A recent meta-analysis ${ }^{3}$ has shown increased plasma levels of different proinflammatory cytokines, including IL- $1 \beta$ and IL-6, in patients with first episode psychosis or in acute relapse, followed by a significant reduction after remission of the psychotic episode. That meta-analysis also reported a significant increase in serum TNF-a levels in subjects in their first episode of psychosis and also in the remission phase. Another interesting finding is that neuroinflammation can indirectly modulate the glutamatergic system by interfering with tryptophankynurenine metabolism and consequently lead to increased levels of kynurenic acid, an endogenous $\mathrm{N}$-methyl-D-aspartate (NMDA) antagonist. ${ }^{4}$

The activation of microglia can be visualized in vivo using positron emission tomography (PET) and the radioisotope $(\mathrm{R})-\left[{ }^{11} \mathrm{C}\right] \mathrm{PK} 11195$. Two studies have found increased binding of this ligand in the brains of patients with recent-onset schizophrenia, suggesting that microglial cells are also more activated in these patients. ${ }^{5,6}$

The aforementioned findings suggest that neuroinflammation may have important effects on patients in different stages of schizophrenia, from pregnancy to the onset of psychotic symptoms. In this sense, the use of anti-inflammatory drugs may potentially improve treatment outcomes.

Cristiano Chaves, Antônio W. Zuardi, Jaime E. C. Hallak

Department of Neuroscience and Behavior, Division of Psychiatry, Faculdade de Medicina de Ribeirão Preto, Universidade de São Paulo, Ribeirão Preto, SP, Brazil. National Science and Technology Institute for Translational Medicine (INCT-TM). 


\section{References}

1. Benros ME, Nielsen PR, Nordentoft M, Eaton WW, Dalton SO, Mortensen PB. Autoimmune diseases and severe infections as risk factors for schizophrenia: a 30-year population-based register study. Am J Psychiatry. 2011;168:1303-10.

2. Brown AS, Derkits EJ. Prenatal infection and schizophrenia: a review of epidemiologic and translational studies. Am J Psychiatry. 2010;167:261-80.

3. Miller BJ, Buckley P, Seabolt W, Mellor A, Kirkpatrick B. Metaanalysis of cytokine alterations in schizophrenia: clinical status and antipsychotic effects. Biol Psychiatry. 2011;70:663-71.

4. Chaves C, Marque CR, Wichert-Ana L, Maia-de-Oliveira JP, Itikawa E, Crippa JA. Minocycline and psychoneuroimmunology in schizophrenia. Prog Neuropsychopharmacol Biol Psychiatry. 2010;34:1133-4.

5. Doorduin J, de Vries EF, Willemsen AT, de Groot JC, Dierckx RA, Klein HC. Neuroinflammation in schizophrenia-related psychosis: a PET study. J Nucl Med. 2009;50:1801-7.

6. van Berckel BN, Bossong MG, Boellaard R, Kloet R, Schuitemaker $A$, Caspers $E$, et al. Microglia activation in recent-onset schizophrenia: a quantitative (R)-[11C]PK11195 positron emission tomography study. Biol Psychiatry. 2008;64:820-2.

\section{Correspondence:}

\section{Cristiano Chaves}

Departamento de Neurociências e Ciências do Comportamento, FMRP, USP

Av. Bandeirantes, 3900

14025-048 - Ribeirão Preto, SP - Brazil

Tel.: +55 (16) 3602.2853

E-mail: crischaves01@yahoo.com.br

Financial support: none.

Submitted Feb 02 2015, accepted for publication Apr 202015. No conflicts of interest declared concerning the publication of this letter.

Suggested citation: Chaves C, Zuardi AW, Hallak JE. The role of inflammation in schizophrenia: an overview [letter]. Trends Psychiatry Psychother. 2015;37(2):104-105. http://dx.doi. org/10.1590/2237-6089-2015-0007 